\title{
EPIDEMIOLOGY OF TRAUMATIC HIP DISLOCATION IN PATIENTS TREATED IN CEARÁ, BRAZIL
}

\author{
luciana Cascão lima ${ }^{1}$, Robson alves do Nascimento ${ }^{1}$, Victor Monte Tenório de Almeida ${ }^{1}$, Fernando Antônio Mendes FaÇanha Filho ${ }^{1}$
}

\begin{abstract}
Objective: To describe the epidemiological profile of patients with traumatic hip dislocation treated in our Institute from November/2012 to July/2013. Methods: A descriptive cross-sectional study based on interviews and involving 43 patients who suffered traumatic hip dislocation was conducted. Results: The mean age of patients was 34.4 years old and $90.7 \%$ were male. Regarding the mechanism of injury, 95\% involved traffic accidents. The posterior dislocation of the hip was the most common injury (93\%). Associated lesions were observed in $74.4 \%$ of patients, hip fractures being the most frequent. The time span between accident and dislocation reduction was
\end{abstract}

less than 6 hours in $37.2 \%$ of patients, between 6 and 12 hours in $32.5 \%$ and over 12 hours in $30.3 \%$, ranging from 1 hour to 15 days. A fraction of $90.7 \%$ of patients was submitted to closed reduction. Conclusion: Traumatic hip dislocation affected mostly young adults, victims of traffic accidents. The posterior dislocation of the hip was the most frequent injury and closed reduction was performed in $90.7 \%$ of patients. The time span between accident and dislocation reduction was less than 12 hours in most patients. Level of Evidence III, Study of Nonconsecutive Patients.

Keywords: Hip dislocation. Epidemiology. Traumatology.

Citation: Lima LC, Nascimento RAl, Almeida VMT, Façanha Filho FAM. Epidemiology of traumatic hip dislocation in patients treated in Ceará, Brazil. Acta Ortop Bras. [online]. 2014;22(3):151-4. Available from URL: http://www.scielo.br/aob.

\section{INTRODUCTION}

Sprains are considered orthopedic urgencies and need early and precise diagnosis. ${ }^{1-3}$ Proper conduct reduces the deleterious effects caused by trauma and subsequent established joint incongruity. The approach to patient with dislocation should occur in the hospital, due to the resources available for proper diagnosis and correct therapeutic approach, especially in those who require anesthesia and operation room resources. ${ }^{2,4}$

Traumatic hip dislocation is a serious orthopedic injury that can cause permanent disability. It is usually caused by high-energy trauma, most frequently related to accidents caused by motor vehicles and their condition are worsened when associated with acetabular or head femoral fracture. ${ }^{2,5,6}$

Posterior dislocation of the hip is the most common, being produced by direct impact on the flexed hip in automobile accidents, the patient showing the affected limb shortened, adducted and with medial rotation. ${ }^{1,7}$

Even avoiding the most immediate complications such as avascular necrosis and wear caused by loose bodies, longterm results of hip dislocation are not satisfactory, having been reported high incidence of hip osteoarthritis (circa $50 \%$ ). ${ }^{8,9}$ Other authors ${ }^{10}$ consider that the results may vary mostly due to the interval between the time of the accident and dislocation reduction. The more the time elapse between dislocation and reduction, the worse the results. These authors ${ }^{10}$ cited other studies in which reduction after 12 hours increased the incidence of unsatisfactory results from $22 \%$ to $52 \%$. For this reason, treatment of hip dislocations should be conducted in a way to avoid complications, through immediate dislocation reduction and achievement of a stable and congruent joint.

The aim of this study was to delineate the epidemiological profile of patients with traumatic hip dislocation treated at Hospital Instituto Dr. José Frota, a tertiary trauma care center in the state of Ceará, Brazil, from November/2012 to July/2013.

\section{MATERIALS AND METHODS}

A cross-sectional descriptive study was performed between November 2012 and July 2013, evaluating forty-three patients with traumatic dislocation of the hip treated at the Hospital Dr. José Frota, Ceará, Brazil.

Inclusion criteria for the study were: 1) Patient treated at the Tertiary Trauma Unit with anterior or posterior traumatic dislocation of the hip; 2) Have preserved consciousness; 3) Consent to participate in the study after explanation of the treatment;

All the authors declare that there is no potential conflict of interest referring to this article.

\section{Hospital Instituto Dr. José Frota, Fortaleza, CE, Brazil.}

Work developed at Serviço de Ortopedia e Traumatologia do Hospital Instituto Dr. José Frota, Fortaleza, CE, Brazil.

Correspondence: Av. Santa Marta, 300, Casa 12, Bairro Precabura, Eusébio, 61760-906 CE, Brazil. lu_lima30@yahoo.com.br

Article received in 09/05/2013, approved in 11/05/2013.

Acta Ortop Bras. 2014;22(3):151-4 
4) Sign the free and informed consent term; 5) Age equal or higher than 18 years old.

Exclusion criteria were: 1) Refusal by the patient to participate in this study after explanation of the treatment; 2) Patient (or his/ her legal representative) unable to answer the questionnaire; 3) Patient presenting central or inveterate dislocation of the hip. After the diagnosis of the lesion, the patient underwent an interview with a previously designed questionnaire. (Annex 1). Data were analyzed using Epilnfo ${ }^{\circledR}$ version 6.04.

The hip dislocations were divided anatomically into anterior and posterior. (Figures 1A, 1B, and 2). Anterior dislocations were classified according to Epstein and Harvey ${ }^{11}$ and posterior ones according to Thompson and Epstein. ${ }^{12}$

This study was authorized by the Institution Research Ethics Committee.

\section{RESULTS}

Between November 2012 and July 201343 patients with traumatic hip dislocation treated at Hospital Instituto Dr. José Frota, Ceará, Brazil were evaluated. Patients' mean age was 34.4 years old, ranging from 18 to 75 years old, $90.7 \%$ of them were males and $9.3 \%$ females.

Regarding the mechanism of injury, 95\% of hip dislocations were caused by traffic accidents, followed by $5 \%$ due to fall from height. The most frequent type of hip dislocation observed was posterior dislocation (93\%), and only $7 \%$ of anterior dislocations. The classification of lesions can be seen in Table 1. Approximately $55.8 \%$ of the patients had associated hip fractures (Figure 3), totalizing 26 lesions in 24 affected patients. Regarding the occurrence of associated lesions, it was noticed that $74.4 \%$ of patients presented such lesions, which are shown in Figure 4.

In $90.7 \%$ of patients closed reduction was performed using the Allis maneuver. In the other cases (9.3\%) an open reduction was required.

The time between the accident and the dislocation reduction varied according to Figure 5, with a minimum time of 1 hour and maximum of 15 days having been observed.

\section{DISCUSSION}

The paucity of epidemiological studies that address the hip dislocations makes it difficult to establish an objective comparison of the obtained results.

We evaluated 43 patients over a nine months period. In our midst, Giordano et al. ${ }^{6}$ analyzed 34 patients during four years and reported complications observed after 18 and 56 months follow-up. Onyemaechi and Eyichukwu ${ }^{13}$ performed similar epidemiological study in 49 patients over five years.

The present study demonstrated that traumatic hip dislocation is quite common in young patients, considering that the mean age of affected patients was 34.4 years old and affects mainly males $(90.7 \%)$, with similar findings as those reported by Giordano et al. ${ }^{6}$ and Onyemaechi and Eyichukwu. ${ }^{13}$

Regarding the mechanism of injury, traffic accidents were responsible for 95\% of dislocations, which is in agreement with the literature. ${ }^{1,6,13,14}$ Tornetta and Mostafavi ${ }^{14}$ stated that the main mechanism is high-energy trauma caused by car accidents.

Studies state that the number of posterior dislocations exceeds the number of anterior dislocations, in a ratio of about $9: 1 .{ }^{18,9,11-13}$

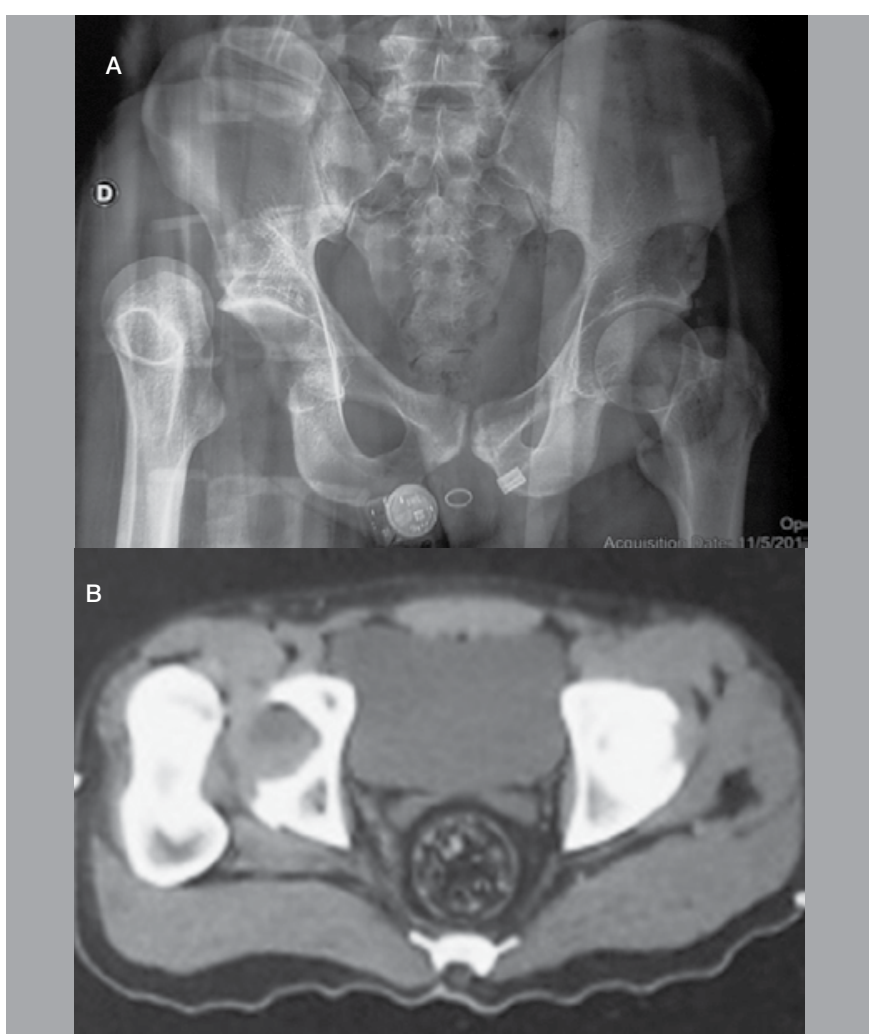

Figure 1. (A) X-Ray of the hip showing Epstein and Harvey type IC anterior sprain of the right hip; (B) Computed tomography showing anterior sprain of the hip and acetabulum fracture.

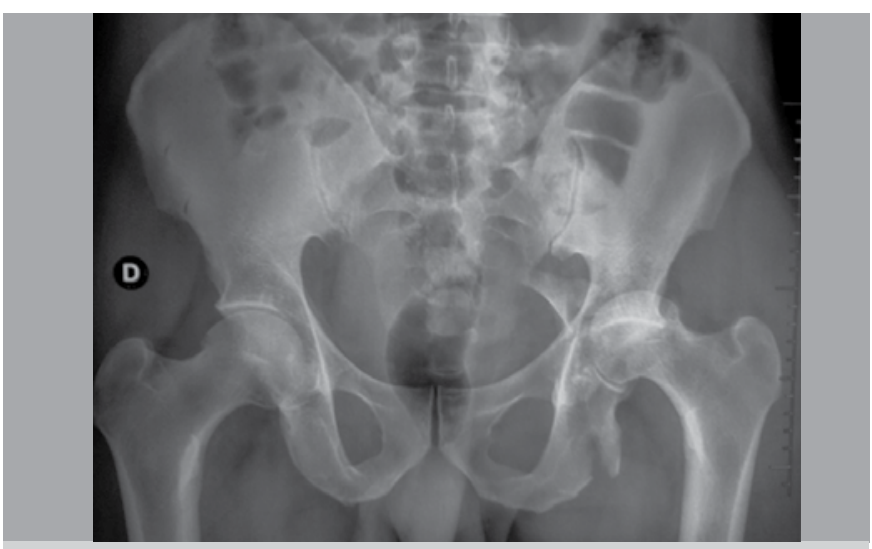

Figure 2. X-Ray of the hip showing Thompson and Epstein type IV posterior sprain of the left hip.

In the present study, we also observed maily posterior dislocations (93\%), and only $7 \%$ anterior dislocations.

Associated lesions were observed in $74.4 \%$ of patients, mostly hip fractures (55.8\%) and head trauma (9.3\%). Suraci ${ }^{15}$ found that $95 \%$ of patients in his study presented other injuries besides hip dislocation.

It is well known that the prognosis of hip dislocation depends on several factors, including the reduction time. ${ }^{10,14,16}$ According to the literature, the incidence of avascular necrosis of the femoral head varies from $1.7 \%$ to $40 \%$, but it may be reduced to 0 to $10 \%$ if the reduction is performed in the first six hours after trauma. ${ }^{10}$ We verified, among our patients, that the time 
Table 1. Demography of evaluated patients. (Fortaleza, 2013)

\begin{tabular}{|c|c|c|c|}
\hline Patient & Gender & Age (years old) & Classification \\
\hline 1 & Male & 18 & $A \| A$ \\
\hline 2 & Female & 26 & PIV \\
\hline 3 & Male & 27 & $A \| A$ \\
\hline 4 & Female & 20 & $\mathrm{PI}$ \\
\hline 5 & Female & 39 & $P \|$ \\
\hline 6 & Male & 38 & $P \|$ \\
\hline 7 & Male & 51 & $\mathrm{PI}$ \\
\hline 8 & Male & 27 & $\mathrm{PI}$ \\
\hline 9 & Male & 31 & $\mathrm{PI}$ \\
\hline 10 & Male & 34 & $\mathrm{PI}$ \\
\hline 11 & Male & 38 & $\mathrm{PI}$ \\
\hline 12 & Male & 29 & $P \mid$ \\
\hline 13 & Male & 75 & $\mathrm{PI}$ \\
\hline 14 & Female & 44 & $P \|$ \\
\hline 15 & Male & 25 & $\mathrm{PI}$ \\
\hline 16 & Male & 42 & $P \|$ \\
\hline 17 & Male & 34 & $P \|$ \\
\hline 18 & Male & 18 & $\mathrm{PI}$ \\
\hline 19 & Male & 21 & $P \|$ \\
\hline 20 & Male & 26 & $\mathrm{PI}$ \\
\hline 21 & Male & 37 & $P \|$ \\
\hline 22 & Male & 44 & $\mathrm{PI}$ \\
\hline 23 & Male & 31 & $\mathrm{PI}$ \\
\hline 24 & Male & 46 & $\mathrm{PI}$ \\
\hline 25 & Male & 26 & $\mathrm{PI}$ \\
\hline 26 & Male & 26 & $P \|$ \\
\hline 27 & Male & 26 & $P \|$ \\
\hline 28 & Male & 36 & $P \|$ \\
\hline 29 & Male & 25 & $\mathrm{PV}$ \\
\hline 30 & Male & 30 & $P \|$ \\
\hline 31 & Male & 50 & $\mathrm{PI}$ \\
\hline 32 & Male & 33 & $P \|$ \\
\hline 33 & Male & 43 & $\mathrm{PI}$ \\
\hline 34 & Male & 29 & $\mathrm{PI}$ \\
\hline 35 & Male & 31 & AIC \\
\hline 36 & Male & 42 & $\mathrm{P} \| \mathrm{II}$ \\
\hline 37 & Male & 23 & $P \| I$ \\
\hline 38 & Male & 32 & $P \|$ \\
\hline 39 & Male & 24 & $P|I|$ \\
\hline 40 & Male & 44 & $\mathrm{P} \| \mathrm{II}$ \\
\hline 41 & Male & 71 & $\mathrm{PI}$ \\
\hline 42 & Male & 32 & PIV \\
\hline 43 & Male & 35 & $\mathrm{PV}$ \\
\hline
\end{tabular}

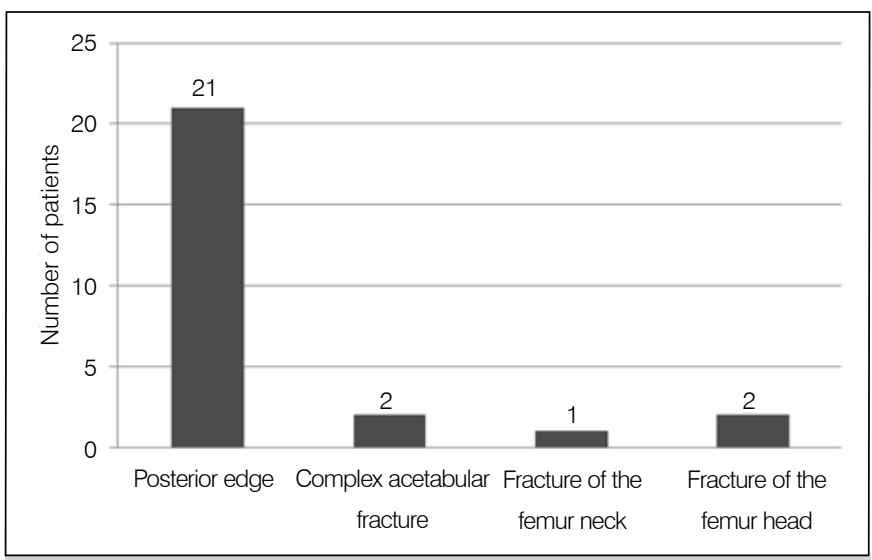

Figure 3. Distribution of associated hip fractures. (Fortaleza, 2013)

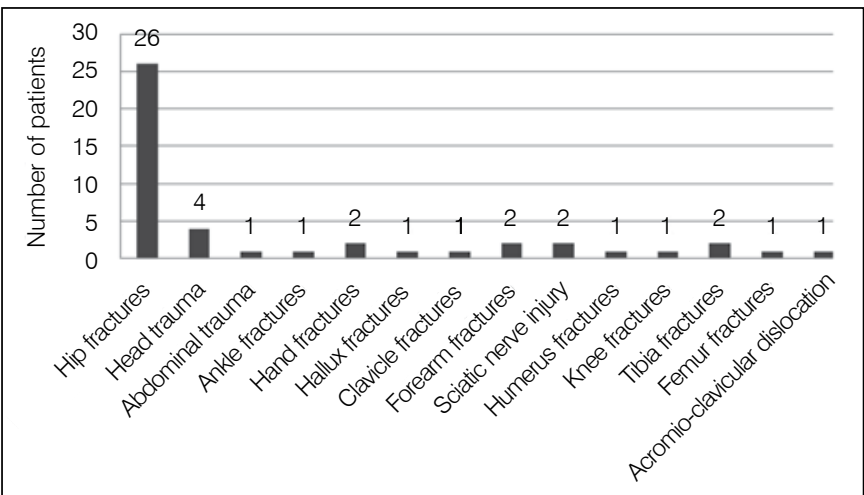

Figure 4. Distribution of associated lesions. (Fortaleza, 2013)

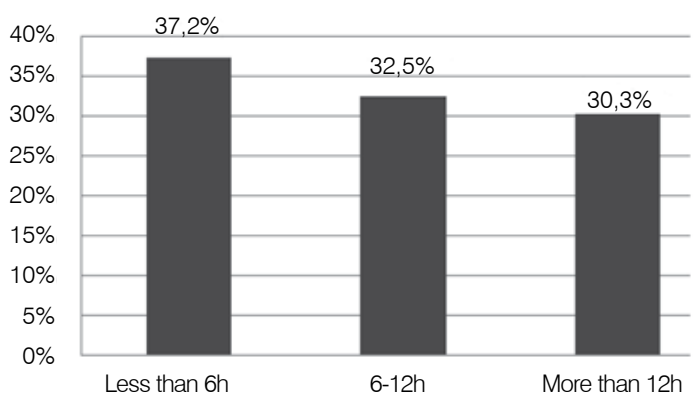

Figure 5. Distribution of patients according to time between accident and injury reduction. (Fortaleza, 2013)

between the accident and dislocation reduction was less than six hours in approximately one third of cases $(37,2 \%)$, ranging from 1 hour to 15 days, and most (69.7\%) had a reduction in less than 12 hours. Although the dislocation is considered an orthopedic emergency, many patients in our study underwent reduction 12 hours after trauma. The delay in the treatment of these patients can be caused by delays in transporting those patients, either due to distance from the crash site, since this service receives patients from various cities in the state, as well as a delay in diagnosis due to professionals attendance by non-trained personnel on secondary care centers, or due to associated injuries that demand priority in emergency care. In our series, a patient waited fifteen days for treatment. He was admitted in our hospital eight days after trauma, during which time he was admitted to the local hospital. This patient presented beyond dislocation, fracture of the femoral neck and ipsilateral acetabular dislocation, and the definitive treatment of choice was total hip arthroplasty.

Giordano et al. ${ }^{6}$ observed that the elapsed time between hospital admission and dislocation reduction ranged from one to five hours. We must point out that this time was lower in our findings, since these authors considered the time of admission as reference, not considering the time elapsed between the accident and hospital admission, which was the case in our study. Regarding the type of dislocation reduction, $90.7 \%$ of our patients underwent closed reduction, all of which were reduced by the Allis maneuver, in agreement with other studies. ${ }^{6,13}$ Closed reduction should always be the first choice in treatment of hip dislocation, unless there is a formal indication to perform an 
open reduction. In general, open reduction is recommended when there is any obstacle to closed reduction (such as intra-articular free-body or soft tissue interposition) or neurological deterioration after sprain reduction, ${ }^{6}$ or yet a proximal femoral fracture or other associated injury which makes impossible manipulating the lower limb to perform the reduction. ${ }^{10}$

\section{CONCLUSION}

The present study showed that traumatic hip dislocation was more frequent in younger patients (mean age 34.4 years) and affected mainly males. Injuries are usually caused by high-energy trauma, $95 \%$ of which were caused by traffic accidents.

\section{REFERENCES}

1. Deakin DE, Porter K. Traumatic hip dislocation in adults. Trauma. 2009;11(3):189-97.

2. Giza E, Mithofer K, Matthews H, Vrahas M. Hip fracture-dislocation in football: a report of two cases and review of the literature. Br J Sports Med. 2004;38(4):e17.

3. Nahas RM, Netto E, Chikude T, Ikemoto R. Fratura-luxação traumática do quadril no futebol: relato de caso. Rev Bras Med Esporte. 2007;13(4):280-2.

4. Goga IE, Gongal P. Severe soccer injuries in amateurs. Br J Sports Med. 2003;37(6):498-501.

5. Sah AP, Marsh E. Traumatic simultaneous asymmetric hip dislocations and motor vehicle accidents. Orthopedics. 2008;31(6):613.

6. Giordano V, Costa PR, Esteves JD, Félix Júnior J, Franklin CE, Amaral NP. Luxações traumáticas do quadril em pacientes esqueleticamente maduros. Rev Bras Ortop. 2003;38(8):462-72.

7. LaVelle DG. Fraturas do quadril. In: Canale ST. Cirurgia ortopédica de Campbell. 10a. ed. Barueri, SP: Manole; 2007. p. 2922-38.

8. Yang RS, Tsuang YH, Yang YS, Liu TK. Traumatic dislocation of the hip. Clin Orthop Relat Res. 1991;(265):218-28.

9. Dreinhofer KE, Schwarzkopf SR, Haas NP, Tscherne H. Isolated traumatic dislocation
The most observed type of hip dislocation was posterior dislocation (93.3\%). Associated injuries were found in $74.4 \%$ of patients and $55.8 \%$ had specifically hip fractures. The time elapsed between the accident and the dislocation reduction was less than 12 hours in most patients (69.7\%). Closed reduction of the dislocation was performed in $90.7 \%$ of cases using Allis maneuver.

There is an urgent need for improvement in care of this kind of trauma victims from the initial management in emergency and definitive traumatology treatment, aiming to reduce the time between the accident and reduction of dislocations, since it directly influences the prognosis.

of the hip. Long term results in 50 patients. J Bone Joint Surg Br.1994;76(1):6-12.

10. Tornetta $P$ 3rd. Luxações do quadril e fraturas da cabeça do fêmur. In: Bucholz RW, Heckman JD. Rockwood e Green fraturas em adultos. 5a. ed. Barueri, SP: Manole; 2006. p.1547-78.

11. Epstein HC, Harvey JP. Traumatic anterior dislocation of the hip. Management and results. J Bone Joint Surg Am. 1972;54:1561-70.

12. Thompson VP, Epstein HC. Traumatic dislocation of the hip; a survey of two hundred and four cases covering a period of twenty-one years. J Bone Joint Surg Am. 1951;33(3):746-78.

13. Onyemaechi NO, Eyichukwu GO. Traumatic hip dislocation at a regional trauma centre in Nigeria. Niger J Med. 2011;20(1):124-30.

14. Tornetta P 3rd, Mostafavi HR. Hip Dislocation: Current Treatment Regimens. J Am Acad Orthop Surg. 1997;5(1):27-36.

15. Suraci AJ. Distribution and severity of injuries associated with hip dislocations secondary to motor vehicle accidents. J Trauma. 1986;26(5):458-60.

16. Hougaard K, Thomsen PB. Traumatic posterior dislocation of the hip-prognostic factors influencing the incidence of avascular necrosis of the femoral head. Arch Orthop Trauma Surg. 1986;106(1):32-5.

Annex 1. Protocol of traumatic sprain of the hip.

Record $\mathrm{N}^{\circ}$ :

Name:

Telephone number

Date of accident :

Mechanism of Trauma: ( ) Traffic accident

( ) Accident during sports practice ( ) other:

Associated injuries caused by accident:

Direction of hip sprain: ( ) anterior ( ) posterior

Associated fractures in the same hip:
( ) Simple posterior edge
( ) femur head
( ) Comminuted posterior edge
( ) simple front edge
( ) Femur neck
( ) comminuted anterior edge
Time elapsed between accident and reduction: hours

Type of reduction:

( ) Closed ( ) Open

When open reduction was performed:

Patient: ( ) Supine ( ) Prone;

Number of people to reduce:

Lateral vector force was exerted by someone? ( ) Yes ( ) No ( ) No need

Patient lied during the maneuver:

( ) In the ground ( ) Transport stretcher ( ) Surgical table

Description of the reduction maneuver:

AP Hip X-Ray ( ) concentric reduction ( ) non-concentric reduction

Classification of the dislocation:

Interviewer 